\title{
A QUESTÃO DA INADMISSIBILIDADE DE PROVAS ILÍCITAS NO PROCESSO PENAL EM FAVOR DO JUIZ: UMA CRÍTICA À POSIÇÃO DO MINISTRO DO SUPREMO TRIBUNAL FEDERAL NUNES MARQUES NO JULGAMENTO DO HABEAS CORPUS N. ${ }^{\circ} 164.493$
}

\author{
Ana Isabel Mendes ${ }^{1}$ \\ Marcelo Martins Piton ${ }^{2}$ \\ Marcos Leite Garcia ${ }^{3}$
}

\section{Resumo}

O presente artigo tem como objetivo analisar a inadmissibilidade de provas ilícitas, que está prevista no artigo $5^{\circ}$, LVI, da Constituição do Brasil de 1988, sendo uma garantia fundamental do cidadão contra abusos do Estado. Como admitir a utilização de provas ilícitas para se comprovar a suspeição do Magistrado, uma vez que na relação processual, é presentante do Estado. Portanto, não se está diante de um conflito de direitos fundamentais envolvendo duas pessoas, mas sim um réu e o Poder Judiciário, que deve ser o garantidor do devido processo legal substancial. O método da pesquisa é o dedutivo.

Palavras-chave: Inadmissibilidade de provas ilícitas; Garantia Fundamental; Suspeição; Arbitrariedades; Devido processo legal substancial.

\section{THE QUESTION OF THE INADMISSIBILITY OF UNLAWFUL EVIDENCE IN CRIMINAL PROCEDURE IN FAVOR OF THE JUDGE: A CRITICISM OF THE POSITION OF THE SUPREME FEDERAL COURT JUSTICE NUNES MARQUES IN THE TRIAL OF HABEAS CORPUS N. ${ }^{\circ} 164.493$}

\begin{abstract}
This article aims to analyze the inadmissibility of unlawful evidence, which is provided for in article 5, LVI, of the Brazilian Constitution of 1988, being a fundamental guarantee of the citizen against abuses by the State. How to admit the use of unlawful evidence to prove the suspicion of the Magistrate, since in the procedural relation, he is a representative of the State. Therefore, we are not facing a conflict of fundamental rights involving two people, but a defendant and the Judiciary, which must be the guarantor of substantial due process of law. The research method is deductive.

\footnotetext{
${ }^{1}$ Graduação em Direito pela Universidade de Passo Fundo - UPF. Mestranda em Direito pela Universidade de Passo Fundo - UPF-RG. Advogada. E.mail: aisabelmendes@ hotmail.com

${ }^{2}$ Graduação em Direito pela URI - Campus Frederico Westphalen. Pós-graduação em direito público. Mestrando em jurisdição constitucional pela Universidade de Passo Fundo. Defensor público do estado do Rio Grande do Sul. E.mail: marcelofw@icloud.com

${ }^{3}$ Doutor em Direitos Fundamentais (2000); Master em Direitos Humanos (1990); ambos cursos realizados no Instituto de Direitos Humanos da Universidade Complutense de Madrid, Espanha. Realizou estágio pós-doutoral na Universidade de Santa Catarina entre 2011e 2012. Desde 2001 professor do Programa de Pós-Graduação Stricto Sensu em Ciência Jurídica, Cursos de Mestrado e Doutorado, e do Curso de Graduação em Direito da Universidade do Vale do Itajaí (UNIVALI)- Santa Catarina. Da mesma maneira, desde 2015 professor do Programa de Pós-Graduação em Direito, Curso de Mestrado, da Universidade de Passo Fundo (UPF) - Rio Grande do Sul. E-mail: mgarcia@univali.br
} 
Key words: Inadmissibility of unlawfull evidence; Fundamental Warranty; Suspicion; Arbitrarities; substantial due process of law.

\section{Introdução}

O presente trabalho tem como objetivo analisar a inadmissibilidade de provas ilícitas no caso do Habeas Corpus $\mathrm{n}^{\mathrm{o}}$ 164.493, a partir de uma crítica à posição do Ministro do Supremo Tribunal Federal Kassio Nunes Marques. Inadmissibilidade de provas ilícitas está expressa no artigo $5^{\circ}$, LVI, da Constituição da República Federativa do Brasil de 1988, sendo, portanto, uma garantia fundamental do cidadão contra abusos dos presentantes do Estado. Assim, o problema, a pergunta de pesquisa, é no sentido de que: deve-se admitir a utilização de prova ilícita para se comprovar a suspeição do Magistrado? Uma vez que o magistrado, na relação processual, é presentante do Estado, e não um cidadão. Portanto, não se está diante de um conflito de direito fundamental envolvendo duas pessoas, mas sim um réu e o Poder Judiciário, presentado pelo Magistrado, que não é titular do direito fundamental de vedação de provas ilícitas, mas sim garantidor do devido processo legal substancial.

É inegável que a atividade probatória ${ }^{4}$ desempenha nítida função de persuasão em relação à sociedade, sendo verdadeiro mecanismo de legitimação por meio do qual a decisão deixa de ser arbitrária e se torna aceitável, razão pela qual os seus limites se consubstanciam em tema de crucial importância (TARUFFO, 2009); (GOMES FILHO, 1999).

Nesse sentido, a inadmissibilidade de provas ilícitas ${ }^{5}$, no processo, está prevista no artigo 5, LVI, da Constituição Federal (BRASIL, 2021). Atualmente, a despeito ser corrente o debate acerca da (im)possibilidade de se admitir provas ilícitas em favor do réu ou

\footnotetext{
${ }^{4}$ Para Michele Taruffo: "La prueba es el instrumento que utilizan las partes desde hace siglos para demostrar la veracidad de sus afirmaciones, y del cual se sirve el juez para decidir respecto a la verdad o falsedad de los enunciados fácticos. En términos muy generales, se entiende como prueba cualquier instrumento, método, persona, cosa o circunstancia que pueda proporcionar información útil para resolver dicha incertidumbre". TARUFFO, Michele. La Prueba Sobre Los Hecho, Colección Estructuras y Processos. Tradução de Jordi Ferrer Beltrán. Imprenta: Madri, 2009.p. 59. Em tradução livre: A prova é o instrumento que as partes utilizam há séculos para demonstrar a veracidade de suas afirmações e que o juiz utiliza para decidir sobre a veracidade ou falsidade de afirmações factuais. Em termos muito gerais, entende-se por evidência qualquer instrumento, método, pessoa, coisa ou circunstância que possa fornecer informações úteis para resolver tal incerteza."

${ }^{5}$ Prova ilícita é aquela que viola norma de direito material ou constitucional, ao passo que ilegítima é aquela que viola norma de direito processual. Vide: GRINOVER, Ada Pellegrini; FERNANDES, Antonio Scarance; FILHO, Antonio Magalhães Gomes. As nulidades no processo penal. 2 ed. São Paulo: Malheiros, 1992.
} 
em favor da acusação (KNIJINI, 2007), o tema ganhou um novo contorno: admite-se prova ilícita para se comprovar a suspeição do Magistrado?

Isso a partir do voto do Ministro do Supremo Tribunal Federal Nunes Marques, no julgamento do Habeas Corpus n. ${ }^{\circ} 164.493^{6}$, que foi contrário à utilização de provas ilícitas para se comprovar a suspeição do órgão julgador.

No caso em apreço, foram obtidas, por meio criminoso, conversas do então Juiz Sérgio Fernando Moro, por meio da invasão do telefone de um Procurador da República. Após a obtenção dos dados, foram verificados inúmeros diálogos entre os órgãos acusador e julgador, que, segundo a defesa, tornavam ele imparcial.

Entendeu o Ministro Nunes Marques que, como houve violação ilícita dos sigilos telefônicos, essa prova seria absolutamente inaceitável, por ser fruto de crime. Mencionou, para isso, os incisos $\mathrm{XII}^{7}$ e $\mathrm{LVI}^{8}$ do artigo $5^{\circ}$ da Constituição Federal. Também ressaltou que, caso fosse permitida a utilização da prova, estar-se-ia a legalizar a atividade de hacker no Brasil e que haveria a legalização da atividade de espionar, bisbilhotar e violar a intimidade das pessoas. Por fim, mencionou que não se combate crime, cometendo crime.

Com a devido respeito que merecem todos os Ministros do STF, essa posição desconsidera, a um só tempo, o porquê da previsão constitucional da vedação a provas ilícitas, bem como a sua posição topológica e a função das garantias fundamentais, conforme será demonstrado.

O método utilizado para a Fase de Investigação e o Relato de Pesquisa será o Dedutivo $^{9}$, cuja premissa maior são as reivindicações da questão da inadmissibilidade das provas ilícitas no Processo Penal, como premissa a ser desenvolvida ao longo do texto, a crítica às posições na matéria de membro do Supremo Tribunal Federal e a vinculação que devem ter com os direitos fundamentais de todo cidadão. As técnicas selecionadas ao

\footnotetext{
${ }^{6}$ Todas as referências ao voto seguem esta fonte: BRASIL. Supremo Tribunal Federal (2. Turma). Habeas Corpus 164.493/PR. Impetrante: Cristiano Zanin Martins e Outros. Paciente: Luiz Inácio Lula da Silva. Coator: Superior Tribunal de Justiça. Relator: Min. Edson Fachin, 09 de março de 2021. Disponível em: http://portal.stf.jus.br/processos/downloadPeca.asp?id=15346606406\&ext=.pdf. Acesso em: 12 jul. 2021.

${ }^{7}$ XII - é inviolável o sigilo da correspondência e das comunicações telegráficas, de dados e das comunicações telefônicas, salvo, no último caso, por ordem judicial, nas hipóteses e na forma que a lei estabelecer para fins de investigação criminal ou instrução processual penal.

${ }^{8}$ LVI - são inadmissíveis, no processo, as provas obtidas por meios ilícitos.

9 “[...] base lógica da dinâmica da Pesquisa Científica que consiste em estabelecer uma formulação geral e, em seguida, buscar as partes do fenômeno de modo a sustentar a formulação geral”. (PASOLD, 2018, p. 215).
} 
cumprimento dos métodos eleitos são a Pesquisa Bibliográfica e Documental ${ }^{10}$, a Categoria ${ }^{11}$ e o Conceito Operacional ${ }^{12}$, quando necessários.

\section{Da previsão da inadmissibilidade de provas ilícitas no texto constitucional}

Uma das questões que devem ser vistas, é a questão da educação jurídica em nosso país. O Brasil se caracteriza por ter uma educação jurídica pouco aprofundada, feita a partir de manuais e de facilitadores (fichas, resumos e livros fácies). Uma educação apenas visando a formação profissional e sem aprofundar os temas. Sem o debate de questões fundamentais. Destaca-se em nossa academia o professor Lênio Streck (2021) em sua crítica ao ensino do Direito no Brasil, assim como uma forte crítica à hermenêutica do Direito. A falha seria do superficial ensino do Direito em nosso país? Como pode um membro de uma Suprema Corte decidir contra algo que está claramente contido em nossa carta constitucional?

O professor Nicolás López Calera ${ }^{13}$, inesquecível Catedrático da Universidade de Granada, durante toda sua vida sempre insistiu, tanto em sala de aula como em sua obra, que o índice de respeito aos direitos humanos serve de parâmetro, de medidor, da evolução de um povo, do real desenvolvimento de uma nação (LÓPEZ CALERA, 1997, p. 206). O Índice de Desenvolvimento Humano (IDH) foi adotado em 1993, a partir da proposta de 1990 de Amartya Sen, em parceria com o paquistanês Mahbub ul Hag, para fazer um contraponto com os frios números da economia, como o Produto Interno Bruto e a renda per capita, baseado em temas fundamentais como saúde, educação e expectativa de vida, ainda assim vivemos uma época de retrocessos em termos de direitos humanos. O fator nível de educação cidadã, educação voltada para os direitos humanos como valores cívicos previstos na Constituição, no sentido de valorização de uma cultura a favor do constitucionalismo democrático não é uma realidade. Infelizmente estão esquecidos ou deixados de lado ditos objetivos da cultura constitucional em nossa absurda atualidade. Na opinião do professor de Granada a

10 “[...] Técnica de investigação em livros, repertórios jurisprudenciais e coletâneas legais". (PASOLD, 2018, p. 217).

11 “[...] palavra ou expressão estratégica à elaboração e/ou à expressão de uma ideia”. (PASOLD, 2018, p. 207).

12 "[...] definição estabelecida ou proposta para uma palavra ou expressão, com o propósito de que tal definição seja aceita para os efeitos da ideia exposta". (PASOLD, 2018, p. 207).

${ }^{13}$ Nicolás María López Calera foi um catedrático de filosofia do direito da Universidade de Granada, com uma vasta obra, infelizmente falecido em dezembro de 2012. Entre sua obra destacam-se os dois volumes da obra Filosofia del Derecho, publicada pela editora Colmares de Granada, Espanha. 
valorização da cidadania deveria ser um dos temas centrais do debate universitário ${ }^{14}$. Certamente que com a escassez cada vez maior de um espaço público, a praça pública agora em latitudes como a do Brasil pode ser um lugar perigoso ou mesmo um lugar privatizado ${ }^{15}$, ou mesmo um Shopping Center $^{16}$, o último local que resta e no qual se deve pensar a Sociedade, no qual se deve debater os reais problemas da Sociedade e do Estado, é a Universidade. Espaço público por excelência. Assim analisando a crise das faculdades de Direito já no início dos anos 1980, López Calera (1980-1981, p. 40) ${ }^{17}$ defende que a universidade não pode se transformar em uma mera escola de formação profissional, pois é na universidade que se deve debater as questões da Sociedade. Se não debatemos os principais problemas da Sociedade nas universidades, se não construímos um pensamento crítico nos bancos universitários, se não refletimos e protestamos no espaço público que deve ser a universidade estamos perdidos. Se a universidade se transforma em uma mera escolinha de formação profissional estamos fritos, cairemos no vazio e seremos presa fácil do autoritarismo e de ideologias reacionárias. Na universidade deve-se fazer o debate sobre os problemas da comunidade em geral. A universidade é o último bastião da Democracia!

Assim, apenas com a promulgação da Constituição Federal de 1988 a inadmissibilidade das provas ilícitas foi alçada como uma questão constitucional.

Analisando a jurisprudência anterior a $1988^{18}$, Carvalho (1995) aduziu que vigorava o "princípio da veracidade da prova", sendo a prova analisada pela carga de

${ }^{14}$ LOPEZ CALERA, Nicolás María. La crisis de las Facultades de Derecho: una cuestión ideológica. Anales de la Cátedra de Francisco Suarez, Granada, n. 20-21, 1980-1981, p. 40.

${ }_{15}$ Nos dias atuais nas cidades brasileiras a praça pública pode ser "cuidada/adotada" por uma empresa privada, o que significa na prática sua quase privatização. Assim a empresa privada em algumas localidades fecha a praça pública com tapumes para que o povo não aceda ao local durante festas populares como o carnaval. E com esse precedente de apropriação do espaço público durante manifestações populares, o que poderá ocorrer? Fato que nos faz lembrar ao poeta Castro Alves em seu conhecido verso do poema O povo ao poder: (...) A praça! A praça é do povo / Como o céu é do condor / É o antro onde a liberdade / Cria águias em seu calor. / Senhor!... pois quereis a praça? / Desgraçada a populaça / Só tem a rua de seu... / Ninguém vos rouba os castelos / Tendes palácios tão belos... / Deixai a terra ao Anteu. (...) Parte do citado verso do poeta baiano é mais conhecido ainda pela paródia que está na música do compositor popular Caetano Veloso: "A praça Castro Alves é do povo / Como o céu é do avião", dizem os primeiros versos da letra de Um Frevo Novo do álbum Muitos Carnavais, que, exaltando o verdadeiro caráter da festa do Carnaval, é assim adaptado aos novos tempos e o condor cede seu lugar ao avião.

${ }^{16}$ Ainda assim há uma cruzada internacional contra a liberdade de reunião, contra a liberdade manifestação política. Veja-se a análise de Gerardo Pisarello e Jaume Asens em: PISARELLO, Gerardo; ASENS Jaume. La bestia sin bozal: en defensa del derecho a la protesta. Madrid: Los Libros de la Catarata. $184 \mathrm{p}$.

${ }^{17}$ LOPEZ CALERA, Nicolás María. La crisis de las Facultades de Derecho, p. 39.

${ }^{18}$ Aproximadamente 170 acórdãos. 
convencimento que continha, abstraída a forma de obtenção, de modo que eventual irregularidade na obtenção era objeto de ilícito administrativo ou penal próprio, não interferindo na sua admissibilidade no processo. Em outras palavras: a prova era admitida, a depender da sua carga de convencimento, ainda que ilícita.

Com a Constituição Federal de $1988^{19} 20$, como já dito, o tema ganhou contornos constitucionais. Aqui, importante se ressaltar que, no Brasil, ocorria a redemocratização, após um golpe militar em que diversos direitos fundamentais, como a inviolabilidade de domicílio, de correspondência e à dignidade da pessoa humana foram desrespeitados ${ }^{21}$.

${ }^{19}$ A obra "A Gênese do Texto da Constituição de 1988", organizada em dois volumes pelo Senado Federal,
apresenta a formação do texto de cada dispositivo da Carta de 1988, desde o Substitutivo 1 do Relator ao Projeto
$\begin{array}{llll}\text { de } \quad \text { Constituição na } & \text { Comissão de Sistematização. }\end{array}$ http://www.senado.leg.br/publicacoes/GeneseConstituicao/pdf/genese-cf-1988-1.pdf. Acessado em 18 jul 2021. Este trecho é peculiar: "Feita com alguma influência das Constituições portuguesa de 1976 e espanhola de 1978, fecundou-se no clima daalma do povo, por isso não se tornou, como outras, uma mera constituição emprestada ou outorgada. Não tem cheiro de Constituição estrangeiracomo tinham as de 1891 e 1934. Não nasceu de costa virada para o futuro, como a de 1946, nem fundada em ideologia plasmada no interessede outros povos como foi a doutrina de segurança nacional, princípio basilar das Constituições de 1967-1969. Algumas das Cartas Políticasanteriores só têm nome de constituição por simples torção semântica, pois não merecem essa denominação, só de si, rica de conteúdo ético-valorativo. Não é constituição, como repositório dos valores políticos de um povo, documento que não provenha do fundo da consciênciapopular, fecundadora de uma autêntica ordem jurídica naciona. Aí está a grande diferença da Constituição de 1988 no constitucionalismo pátrio que fora sempre dominado por uma elite intelectual que sempre ignorou profundamente o povo brasileiro" (destaque nosso). p. 26.

${ }^{20}$ O discurso da promulgação de ULYSSES GUIMARÃES merece ser lembrado: "Traidor da Constituição é traidor da Pátria. Conhecemos o caminho maldito. Rasgar a Constituição, trancar as portas do Parlamento, garrotear a liberdade, mandar os patriotas para a cadeia, o exílio e o cemitério. Quando após tantos anos de lutas e sacrifícios promulgamos o Estatuto do Homem da Liberdade e da Democracia bradamos por imposição de sua honra. Temos ódio à ditadura. Ódio e nojo." Disponível em: https://www.camara.leg.br/radio/programas/277285-integra-do-discurso-presidente-da-assembleia-nacionalconstituinte-dr-ulysses-guimaraes-10-23/. Acessado em 18 jul. 2021.

${ }^{21} \mathrm{O}$ tema é tão caro que houve a criação da Comissão Nacional da Verdade, em 18.11.2011, por meio da Lei n. ${ }^{\circ}$ 12.582/11, com o fim de examinar e esclarecer as graves violações de direitos humanos praticadas no período de 18.07.1946 a 05.10.1988, a fim de efetivar o direito à memória e à verdade histórica e promover a reconciliação nacional.

O relatório foi apresentado em 10.12.2014, sendo riquíssimo em detalhes, conforme se nota dos seguintes trechos: "No âmbito desse quadro de graves violações de direitos humanos, a CNV teve condições de confirmar 434 mortes e desaparecimentos de vítimas do regime militar, que se encontram identificados de forma individualizada no Volume III deste Relatório, sendo 191 os mortos, 210 os desaparecidos e 33 os desaparecidos cujos corpos tiveram seu paradeiro posteriormente localizado, um deles no curso do trabalho da CNV. Esses números certamente não correspondem ao total de mortos e desaparecidos, mas apenas ao de casos cuja comprovação foi possível em função do trabalho realizado, apesar dos obstáculos encontrados na investigação, em especial a falta de acesso à documentação produzida pelas Forças Armadas, oficialmente dada como destruída. Registre-se, nesse sentido, que os textos do Volume II deste Relatório correspondentes às graves violações perpetradas contra camponeses e povos indígenas descrevem um quadro de violência que resultou em expressivo número de vítimas."

Relatório da Comissão da Verdade. Disponível em: cnv.memoriasreveladas.gov.br/images/documentos/Capitulo17/Capitulo 17.pdf. Acesso em: 07 jul. 2021.

"As graves violações de direitos humanos ocorridas entre 1964 e 1985 decorreram de modo sistemático da formulação e implementação do arcabouço normativo e repressivo idealizado pela ditadura militar com o expresso objetivo de neutralizar e eliminar indivíduos ou grupos considerados como ameaça à ordem interna. 
Nota-se, assim, a clara preocupação do Poder Constituinte Originário diante das graves violações de direitos fundamentais perpetradas durante o Golpe Militar, de modo que essa deve ser a primeira premissa para a compreensão do tema.

Tanto é que, antes de tratar da estrutura do Estado, a Constituição Federal positivou os direitos e garantias fundamentais. Ainda, como observado por Streck (2002, p. 110):

Nunca é demais repetir que o Estado Democrático de Direito assenta-se em dois pilares: a democracia e os direitos fundamentais. Não há democracia sem o respeito e a realização dos direitos fundamentais-sociais, e não há direitos fundamentais-sociais - no sentido que lhe é dado pela tradição - sem democracia. Há assim uma copertença entre ambos.

E, para se restaurar e garantir a democracia, a Constituição Cidadã trouxe, no seu artigo $5^{\circ}$, um amplo catálogo de direitos e garantias fundamentais, que tem como sujeito ativo o cidadão e passivo o Estado, quando falamos dos direitos processuais penais, sendo, pois, verdadeira exigência democrática (SOARES, 2018).

\section{Da posição topológica da proibição da de provas ilícitas}

Importante, também, ressaltar que a previsão se deu no Título II - Dos Direitos e Garantias Fundamentais e no Capítulo I - Dos Direitos e Deveremos Individuais e Coletivos.

Cumpre mencionar, nesse sentido, que o documento intitulado 'Diretrizes de segurança interna' e o seu correspondente Sistema de Segurança Interna tiveram como fundamento a Lei de Segurança Nacional então vigente (Decreto-Lei no 314, de 13 de março de 1967), que transformou em preceitos jurídicos os princípios da Doutrina de Segurança Nacional, disseminada na Escola Superior de Guerra desde o final da década de 1940 e que estabeleceu como corolário a lógica do inimigo interno (...) As graves violações de direitos humanos cometidas durante o período da ditadura militar foram expressão, portanto, de decisões políticas adotadas por suas instâncias dirigentes, que se refletiram nas estruturas administrativas organizadas com base nos princípios da hierarquia e da disciplina, sob a forma de rotinas de trabalho e de padrões de conduta. Houve, nesse sentido, permanente ascendência hierárquica sobre a atividade funcional e administrativa realizada pelos agentes públicos diretamente associados ao cometimento de graves violações de direitos humanos. No âmbito de cadeias de comando solidamente estruturadas, esses agentes estiveram ordenados em escalões sucessivos, por vínculo de autoridade, até o comando máximo da Presidência da República e dos ministérios militares. É possível afirmar, desse modo, que as ações que resultaram em graves violações de direitos humanos estiveram sempre sob monitoramento e controle por parte dos dirigentes máximos do regime militar, que previram, e estabeleceram, mecanismos formais para o acompanhamento das ações repressivas levadas a efeito.”. Relatório da Comissão da Verdade. Disponível em: http://cnv.memoriasreveladas.gov.br/images/pdf/relatorio/Capitulo\%2016.pdf. Acesso em: 07 jul. 2021. 
Resta claro, portanto, que a proibição de provas ilícitas é um direito e garantia fundamental e individual. E acerca dos direitos e garantias fundamentais, aduz Mendes (2004, p. 25)

\begin{abstract}
Os direitos fundamentais são, a um só tempo, direitos subjetivos e elementos fundamentais da ordem constitucional objetiva. Enquanto direitos subjetivos, os direitos fundamentais outorgam aos titulares a possibilidade de impor os seus interesses em face dos órgãos obrigados. Na sua dimensão como elemento fundamental da ordem constitucional objetiva, os direitos fundamentais - tanto aqueles que não asseguram, primariamente, um direito subjetivo quanto aqueloutros, concebidos como garantias individuais forma a base do ordenamento jurídico de um Estado de Direito democrático.
\end{abstract}

Após a revolução francesa, há uma mudança de parâmetros, de modo que a preponderância jurídica é transferida do Estado para os indivíduos; a soberania é deslocada do Estado para a Nação ou povo (MENDES 2016), conforme defendido por Sieyés (2015). Em outras palavras: na dicotomia público/privado, a supremacia passa a ser do segundo elemento (SARMENTO, 2006).

Portanto, os direitos e garantias fundamentais surgem como uma forma de limitação do poder estatal; consequentemente, traduzem-se em direitos dos cidadãos contra arbitrariedades do Estado (MENDES, 2016).

E nesse contexto se mencionam os direitos fundamentais de primeira dimensão, criados para fornecer ao cidadão direitos e garantias, a fim de evitar abusos por parte do Estado, sendo verdadeiros direitos de resistência (MENDES, 2016); (MELLO, 2015).

Merece destaque, nessa linha, o status negativo dos direitos de primeira dimensão, segundo a teoria dos quatro status de Jellinek (1892) que tem como objetivo isolar juridicamente o indivíduo do Estado, culminando numa proteção da sua liberdade e uma limitação das possibilidades de atuação do Estado.

Como se vê, há um claro cunho individualista neles, sobrepondo os direitos do indivíduo perante o Estado; é este quem deve servir àquele, e não o contrário (BITTAR; ALMEIDA, 2002).

Portanto, os direitos fundamentais, especialmente aqueles processuais e penais, não são recompensas, mas conquistas. E conquistas que não se dirigem contra qualquer pessoa, mas unicamente contra o Estado e "contra os entraves à liberdade por ele controlados ou controláveis" (MICHAELS; MORLOK, 2016, p. 48). Daí por que se pode afirmar que a 
importância clássica desses direitos reside na limitação ou prevenção das ingerências do Estado.

Na mesma linha, os direitos fundamentais cumprem, no dizer de Canotilho (1998,

p. 541):

\begin{abstract}
A função de direitos de defesa dos cidadãos sob uma dupla perspectiva: (1) constituem, num plano jurídico-objectivo, normas de competência negativa para os poderes públicos, proibindo fundamentalmente as ingerências destes na esfera jurídica individual; (2) implicam, num plano jurídico-subjectivo, o poder de exercer positivamente direitos fundamentais (liberdade positiva) e de exigir omissões dos poderes públicos, de forma a evitar agressões lesivas por parte dos mesmos (liberdade negativa).
\end{abstract}

Eis a segunda premissa, portanto.

\title{
3. Da necessidade de se interpretar a proibição à luz da Constituição
}

Feitas essas considerações, pode-se afirmar que toda a interpretação dos limites e alcances da proibição de provas ilícitas deve levar em consideração o status conferido a ela pela Constituição Federal, e não partir da legislação infraconstitucional.

Pois bem. Acerca da interpretação constitucional, adverte Barroso (2008, p. 111) que, embora a Constituição Federal seja uma lei, e como tal deve ser interpretada, possui ela uma posição destacada no sistema, diante das suas peculiaridades, notadamente "[...] a) a superioridade hierárquica; b) a natureza da linguagem; c) o conteúdo específico; d) o caráter político".

Já o Ministro Marco Aurélio Mello, em julgamento no Supremo Tribunal Federal, assentou:

Sempre tenho presente a premissa de que o Direito é ciência e, como tal, possui institutos, expressões e vocábulos com sentido próprio, havendo de se presumir que o legislador, especialmente o constituinte, haja atuado com técnica, atentando para o fato de que o esmero da linguagem é essencial à revelação do sentido correto da disposição normativa. (BRASIL, 1992, p. 323, grifo nosso)

Nota-se, assim, que a posição topológica diz muito acerca do tema. 
Ora, se fosse o objetivo instituí-lo como garantia do Estado $^{22}$, não estaria no Título II - Dos Direitos e Garantias Fundamentais e no Capítulo I - Dos Direitos e Deveremos Individuais e Coletivos. E, indubitavelmente, os direitos e garantias fundamentais previstos no artigo 5 são os de primeira dimensão.

Ainda, já advertia Peter Haberle que o "[...] espíritu de las Constituciones resulta palpable em los textos constitucionales, sobre todo en su 'evolución', concebida contemporánea e históricamente como proceso de etapas textuales." (HÄBERLE, 2003). E a evolução ${ }^{23}$ deixa claro a intenção do constituinte: a inadmissibilidade de provas ilícitas é um direito do réu.

Outrossim, o intérprete do texto constitucional não é livre para escolher os topoi ou as premissas, já que, por mais que se valha da sistemática concretizante, está vinculado à Constituição Federal (HESSE, 1998). Se isso fosse admitido, teria o intérprete mais poderes do que aqueles outorgados pelo texto Maior, subvertendo a própria lógica da supremacia constitucional.

Na mesma linha, Kelsen (1998, p. 98) aduz que “[...] toda sentença que viola um direito e garantia fundamental tem o seu conteúdo como inconstitucional, podendo, por esse motivo, ser anulada".

\section{Da proibição de prova ilícita para se comprovar a suspeição do presentante do Poder}

\section{Judiciário}

Como já dito, no julgamento do $\mathrm{HC}$ n. ${ }^{\circ}$ 164.493, o Ministro Nunes Marques se manifestou contrário à utilização de provas ilícitas para se comprovar a suspeição do órgão julgador. Dentre outros argumentos ${ }^{24}$, partiu ele do pressuposto de que o Juiz possui um direito fundamental individual de não se admitir a juntada no processo criminal de uma prova ilícita para comprovar a sua imparcialidade.

Com o devido respeito, a premissa, por si só, já é equivocada.

O Magistrado, no exercício da sua função, nada mais é do que um presentante do Poder Judiciário, que é um dos Poder da República Federativa do Brasil. Não se está diante de

${ }^{22}$ E se fala como garantia do Estado pois o Juiz nada mais é do que um presentante do Poder Judiciário, que é um poder do Estado. Ele é um cidadão, por evidente, mas quando está exercendo o seu cargo, presenta o Estado.

${ }^{23}$ Positivação como um direito fundamental individual.

${ }^{24}$ Mencionados no capítulo 1. 
um conflito de direito fundamental individual envolvendo duas pessoas, mas sim um réu e o Poder Judiciário, presentado pelo Magistrado. Tanto é assim que Pontes de Miranda elaborou a teoria da presentação (PONTES DE MIRANDA, 1974).

Inclusive, eventual ação indenizatória deve ser ajuizada em face do Estado, conforme tese fixada no Tema $940^{25}$ da repercussão Geral do Supremo Tribunal Federal.

$\mathrm{E}$, em nenhum momento da história, direitos e garantias fundamentais individuais criminais foram instituídos em favor de presentantes dos Poderes do Estado quando do exercício da função constitucional! E exatamente por esse motivo sequer há de se falar em princípio da proporcionalidade ${ }^{26}$.

Inclusive, corroborando, Ferrajoli (2011) afirma que as garantias constitucionais "[...] son las garantías de la rigidez de los principios y de los derechos constitucionalmente establecidos que gravan de manera específica a los poderes del Estado" (FERRAJOLI, 2001, p. 40, grifo nosso).

No mesmo sentido, Bonavides (2008, p. 561) afirma que "os direitos fundamentais propriamente ditos são, na essência, [...], os direitos do homem livre e isolado, direitos que possui em face do Estado".

Entender da forma exposta no voto é desconsiderar a história e a função dos direitos fundamentais, especialmente os processuais e criminais: positivar limites ao Poder do Estado. É desconhecer o que é um direito e garantia fundamental. É desconhecer o que significa uma Constituição.

E, mesmo que de forma equivocada se partisse da premissa de que o Estado possui esse direito fundamental, e aí sim se falaria em aplicação do princípio da proporcionalidade, ele cederia frente ao do devido processo legal: todo acusado tem o direito de ser julgado por um juiz imparcial, de modo que a interpretação deve ser no sentido de se permitir a prova; do contrário, estaríamos a admitir um julgamento criminal imparcial e, portanto, violador do devido processo legal.

\footnotetext{
25 “A teor do disposto no art. $37, \S 6^{\circ}$, da Constituição Federal, a ação por danos causados por agente público deve ser ajuizada contra o Estado ou a pessoa jurídica de direito privado prestadora de serviço público, sendo parte ilegítima para a ação o autor do ato, assegurado o direito de regresso contra o responsável nos casos de dolo ou culpa".

${ }^{26}$ E o mesmo pode ser dito quando se fala em utilização de prova ilícita em favor da acusação. O EstadoAcusador não é titular de direitos fundamentais. Nunca foi e nunca será. Afirma isso é desconhecer, por completo, o que é um direito e garantia fundamental.
} 
Inclusive, o direito de ser julgado por um Magistrado imparcial ${ }^{27}$ é previsto no inciso $\operatorname{LIV}^{28}$ do artigo $5^{\circ}$ da Constituição Federal como sendo um direito e garantia fundamental individual, também.

$\mathrm{Na}$ mesma linha, a República Federativa do Brasil é signatária de tratados internacionais que expressamente garantem a todo ser humano, de forma igualitária, julgamento por tribunal independente e imparcial, notadamente a Convenção Americana Sobre Direitos Humanos ${ }^{29}$, a Declaração Universal dos Direitos Humanos ${ }^{30}$ e o Pacto Internacional dos Direitos Civis e Políticos ${ }^{31}$, inclusive incorporados pela Constituição Federal pelo rito previsto no seu artigo $5^{\mathrm{o}}, \S 3^{\mathrm{o} 32}$, possuindo, portanto, status de supralegalidade.

Mas, repita-se, como o presentante do Poder Judiciário não é titular do direito fundamental individual à vedação de provas ilícitas, sequer é necessário esse raciocínio ou a utilização do princípio da proporcionalidade. Esse discrímen é extremamente importante.

Outrossim, quanto à utilização de provas ilícitas em favor do réu, a fim de demonstrar a sua inocência, a doutrina e a jurisprudência são majoritariamente favoráveis em razão exatamente disso: o artigo $5^{\circ}$, LVI, é uma garantia do réu e todas as suas prescrições assim deve ser interpretadas.

\footnotetext{
${ }^{27}$ O Tribunal Europeu de Direitos Humanos, no caso Piersack vs. Bélgica, analisa a imparcialidade só dois aspectos: subjetivo e objetivo. O primeiro diz respeito ao íntimo da convicção do Magistrado, ao passo que o segundo diz respeito à postura do julgador. Vide: Tribunal Europeu de Direitos Humanos. Caso Piersack vs. Belgium: Application $\mathrm{n}^{\circ}$ 8692. 1 out. 1982. Disponível em: http://hudoc.echr.coe.int/eng?i=00157557\#\{"itemid":["001-57557"]\}. Acesso em: 12 jul. 2021.

${ }_{28}^{28}$ LIV - ninguém será privado da liberdade ou de seus bens sem o devido processo legal.

${ }^{29}$ Artigo 8. Garantias judiciais: "1. Toda pessoa tem direito a ser ouvida, com as devidas garantias e dentro de um prazo razoável, por um juiz ou tribunal competente, independente e imparcial, estabelecido anteriormente por lei, na apuração de qualquer acusação penal formulada contra ela, ou para que se determinem seus direitos ou obrigações de natureza civil, trabalhista, fiscal ou de qualquer outra natureza".

${ }^{30}$ Artigo $10^{\circ}$ : "Toda a pessoa tem direito, em plena igualdade, a que a sua causa seja equitativa e publicamente julgada por um tribunal independente e imparcial que decida dos seus direitos e obrigações ou das razões de qualquer acusação em matéria penal que contra ela seja deduzida".

${ }^{31}$ Artigo 14: "1. Todas as pessoas são iguais perante os tribunais e as cortes de justiça. Toda pessoa terá o direito de ser ouvida publicamente e com devidas garantias por um tribunal competente, independente e imparcial, estabelecido por lei, na apuração de qualquer acusação de caráter penal formulada contra ela ou na determinação de seus direitos e obrigações de caráter civil. A imprensa e o público poderão ser excluídos de parte da totalidade de um julgamento, quer por motivo de moral pública, de ordem pública ou de segurança nacional em uma sociedade democrática, quer quando o interesse da vida privada das Partes o exija, que na medida em que isso seja estritamente necessário na opinião da justiça, em circunstâncias específicas, nas quais a publicidade venha a prejudicar os interesses da justiça; entretanto, qualquer sentença proferida em matéria penal ou civil deverá torna-se pública, a menos que o interesse de menores exija procedimento oposto, ou processo diga respeito à controvérsia matrimoniais ou à tutela de menores".

32 Os tratados e convenções internacionais sobre direitos humanos que forem aprovados, em cada Casa do Congresso Nacional, em dois turnos, por três quintos dos votos dos respectivos membros, serão equivalentes às emendas constitucionais.
} 
Grinover, Fernandes e Gomes Filho (1992, p. 409) assim se manifestaram quanto ao tema:

É natural que no confronto entre uma proibição de prova, ainda que ditada pelo interesse de proteção a um direito fundamental, e o direito à prova da inocência este último deve prevalecer, não só porque a liberdade e a dignidade da pessoa humana constituem valores insuperáveis, na ótica da sociedade democrática, mas também porque ao próprio Estado não pode interessar a punição do inocente, o que poderia significar a impunidade do verdadeiro culpado.

Ora, se a proibição de provas ilícitas é uma garantia fundamental individual do réu, nada mais lógico do que, se a prova ilícita a ele aproveita, deve ser utilizada. Do contrário, a garantia se transmudaria em um gravame.

E, segundo Bellamy (2010, p. 75): "El mayor peligro asociado al gobierno de las personas es la posibilidad de decisiones arbitrarias. (...), la presencia de un gobierno capaz de actuar sistemáticamente de modo arbitrario implica dominación”. E nada mais arbitrário do que negar ao cidadão o acesso a uma prova que demonstre a sua inocência.

E a mesma premissa deve ser aplicada para se permitir que se utilize uma prova ilícita para se comprovar que o Estado está sendo imparcial na condução do julgamento.

Ainda, nem de perto se legalizará a atividade de hacker no Brasil ou estimulará a conduta mencionada como ilícita. Isso pois o Código Penal, no seu artigo 154-A, comina uma pena de 01 (um) a 04 (quatro) anos para a conduta de invadir dispositivo informático de uso alheio, conectado ou não à rede de computadores, com o fim de obter, adulterar ou destruir dados ou informações sem autorização expressa ou tácita do usuário do dispositivo ou de instalar vulnerabilidades para obter vantagem ilícita (BRASIL, 1940).

\section{Considerações Finais}

$\mathrm{Na}$ realidade, estar-se-á a vedar condutas antidemocráticas por parte dos presentantes dos Poderes do Estado sejam toleradas, ainda que a descoberta se dê por meios 
ilícitos, especialmente quando está em jogo a liberdade do acusado, tão cara ao Estado Democrático de Direito $^{33}$.

Do mesmo modo, a permissão de provas ilícitas em favor do réu não autoriza que ele cometa crimes, eis que apenas será utilizada se for necessária para provar a sua inocência. E a liberdade (inocência) é, repita-se, um valor imprescindível para que se possa falar em Estado Democrático de Direito.

E não se pode perder de vista, e isso é importantíssimo, que esses argumentos apenas podem ser utilizados para se fundamentar eventual alteração legislativa ${ }^{34}$, mas jamais para se afastar a aplicação do texto legal.

Isso pois, mesmo que de fato a vedação de provas ilícitas em favor do réu, aplicada como posta ${ }^{35}$, fomente condutas ilícitas ou para que culpados sejam inocentados, ela deve ser aplicada, eis que apenas fundamentos de inconstitucionalidade permitem que texto legal seja afastado, e claramente não é o caso. Assim, a opção do Poder Constituinte originário deve ser observada até que alterada, aí sim com base nesses argumentos.

Temos duas expressões que bem resumem isso: argumentos de lege data ${ }^{36}$ ou de lege ferend $a^{37}$. Há, atualmente, clara má técnica ao se valer de argumentos de lege ferenda como se de lege data fossem. Isto é: os motivos pelos quais o jurista entende que uma lei é certa ou errada não interessam, desde que ela seja constitucional. Esses motivos podem fundamentar a elaboração de lei futura dispondo do tema de modo diverso, apenas. Enquanto isso não ocorre, o texto vigente é de aplicação impositiva.

Assim, enquanto a inviabilidade de provas ilícitas for um direito e garantia fundamental individual dos cidadãos ${ }^{38}$, deve ser admitida uma prova ilícita que demonstre a ausência de parcialidade do presentante do Poder Judiciário. Pensar de outra forma é

\footnotetext{
${ }^{33} \mathrm{O}$ artigo $5^{\circ}$ da Constituição Federal aduz que a liberdade é inviolável, além de o preâmbulo aduzir que: "Nós, representantes do povo brasileiro, reunidos em Assembléia Nacional Constituinte para instituir um Estado Democrático, destinado a assegurar o exercício dos direitos sociais e individuais, a liberdade, a segurança, o bem-estar, o desenvolvimento, a igualdade e a justiça como valores supremos de uma sociedade fraterna, pluralista e sem preconceitos, fundada na harmonia social e comprometida, na ordem interna e internacional, com a solução pacífica das controvérsias, promulgamos, sob a proteção de Deus, a seguinte CONSTITUIÇÃO DA REPÚBLICA FEDERATIVA DO BRASIL.” (GRIFO NOSSO)

${ }^{34} \mathrm{E}$, nesse caso, apenas com uma nova constituição.

${ }^{35}$ É, claramente, uma opção de política criminal, que tem prós e contras, mas que jamais pode ser tida como inconstitucional.

${ }^{36}$ Da lei criada.

${ }^{37}$ Da lei a ser criada.

${ }^{38}$ E isso foi uma opção do Poder Constituinte Originário.
} 
desconsiderar, como já dito, o porque da previsão constitucional da vedação a provas ilícitas, bem como a sua posição topológica, e a função dos direitos e garantias fundamentais.

\section{REFERÊNCIAS}

BARROSO, Luís Roberto. Interpretação e Aplicação da Constituição. 7. ed. Editora Saraiva, 2008.

BELLAMY, Richard. Constitucionalismo político: una defesa republicana de la constitucionalidad de la democracia. Tradução de Jorge Urdánoz Ganuza y Santiago Gallego Aldaz. Madrid: Marcial Pons, 2010.

BITTAR, Eduardo C. B.;ALMEIDA, Guilherme Assis de. Curso de Filosofia do Direito. 2 ed. São Paulo: Atlas, 2002.

BRASIL. Código Penal. Portal Planalto. Brasília, DF. 1940 Disponível em: http://www.planalto.gov.br/ccivil_03/decreto-lei/del3914.htm.

BRASIL. Constituição da República Federativa do Brasil de 1988. Texto consolidado até a EC n. 106/2021. Portal Planalto. Brasília, DF. Disponível em: http://www.planalto.gov.br/ccivil_03/constituicao/constituicao.htm.

BRASIL. Relatório da Comissão da Verdade. Disponível em: http://cnv.memoriasreveladas.gov.br/images/pdf/relatorio/Capitulo\%2016.pdf.

BRASIL. Supremo Tribunal Federal (2. Turma). Habeas Corpus 164.493/PR. Impetrante: Cristiano Zanin Martins e Outros. Paciente: Luiz Inácio Lula da Silva. Coator: Superior Tribunal de Justiça. Relator: Min. Edson Fachin, 09 de março de 2021. Disponível em: http://portal.stf.jus.br/processos/downloadPeca.asp?id=15346606406\&ext=.pdf.

BRASIL. Supremo Tribunal Federal (2. Turma). Recurso Ordinário em Mandado de Segurança 21514-3/DF. Recorrente: Confederação Nacional da Agricultura e Outros. Recorrida: União Federal. Relatora: Min. Marco Aurélio, 08 de setembro de 1992. Disponível em: https://redir.stf.jus.br/paginadorpub/paginador.jsp?docTP=AC\&docID=115597.

BONAVIDES, Paulo. Curso de direito constitucional. 23. ed. São Paulo: Malheiros Editores Ltda, 2008.

CANOTILHO, José Gomes. Direito constitucional e teoria da constituição. 4 ed. Coimbra: Almedina, 1998. 
CARVALHO, Ricardo Cintra Torres de. A inadmissibilidade de prova ilícita no processo penal: um estudo comparativo das posições brasileiras e norte-americana. Revista Brasileira de Ciências Criminais, 3(12): 1995.

DIMOULIS, Dimitri; MARTINS, Leonardo. IMOULIS, Dimitri; MARTINS, Leonardo. Teoria Geral dos Direitos Fundamentais. 4 ed. São Paulo: Atlas, 2012.

FERRAJOLI, Luigi. Poderes Salvajes: La crisis de la democracia constitucional. Tradução de Perfecto Andrés Ibáñes. Madrid: Editorial Trotta, S.A, 2011.

GOMES FILHO, Antônio Magalhães. Proibição das Provas Ilícitas na Constituição de 1988. In. MORAIS, Alexandre de. (Org.). Os dez anos da constituição federal. São Paulo: Atlas, 1999.

GRINOVER, Ada Pellegrini; FERNANDES, Antonio Scarance; FILHO, Antonio Magalhães Gomes. As nulidades no processo penal. 2 ed. São Paulo: Malheiros, 1992.

HÄBERLE, Peter. El Estado Constitucional. Tradução de Héctor Fix-Fierro. Universidad Nacional Autónoma de México: Cidade do México, 2003.

HESSE, Konrad. Elementos de Direito Constitucional da República Federal da Alemanha. Porto Alegre: Sergio Antonio Fabris Editor, 1998.

JELLINEK, Georg. System der subjektiven öffentjichen Rechte. Freiburg. Mohr, 1892 apud DIMOULIS, Dimitri; MARTINS, Leonardo. IMOULIS, Dimitri; MARTINS, Leonardo. Teoria Geral dos Direitos Fundamentais. 4 ed. São Paulo: Atlas, 2012. p. 49-55.

KELSEN, Hans. Teoria Pura do Direito. 6. ed. São Paulo: Martins Fontes, 1998.

KNIJINI, Danilo (org). Prova Judiciária: Estudos Sobre O Novo Direito Probatório. Porto Alegre: Livraria do Advogado, 2007.

LOPEZ CALERA, Nicolás María. Filosofía del derecho (I). Granada: Colmares, 1997.

LOPEZ CALERA, Nicolás María. La crisis de las Facultades de Derechos: una cuestión ideológica. Anales de la Cátedra de Francisco Suarez, Granada, p. 39-46, n. 20-21, 19801981.

MENDES, Gilmar Ferreira. Direitos fundamentais e controle de constitucionalidade. 3. ed. São Paulo: Editora Saraiva, 2004. 
MENDES, Gilmar Ferreira; BRANCO, Paulo Gustavo Gonet. Curso de Direito Constitucional. 11 ed. São Paulo: Saraiva, 2016.

MICHAELS, Lothar; MORLOK, Martin. Direitos fundamentais. São Paulo: Editora Saraiva, 2016.

MIRANDA, Francisco Cavalcanti Pontes de.,Tratado de Direito Privado - Parte Geral Tomo I - Introdução. Pessoas Físicas e Jurídicas. 4.ed. São Paulo: RT, 1974.

PASOLD, Cesar Luiz. Metodologia da pesquisa jurídica: teoria e prática. 14. ed. rev. atual. e ampl. Florianópolis: Empório Modara, 2018.

SARMENTO, Daniel. Direitos Fundamentais e Relações Privadas. 2 ed. Rio de Janeiro: Editora Lumen Juris, 2006.

SIEYÈS, Emmanuel Joseph. A Constituinte Burguesa (Qu'est-ce que le Tiers État?). Organização e introdução analítica de Aurélio Wander Bastos. Trad. Norma Azevedo. 6 ed. Rio de Janeiro: Freitas Bastos.

SOARES, Ricardo Maurício Freire. Hermenêutica e Interpretação Jurídica. São Paulo: Editora Saraiva, 2018.

STRECK, Lênio. Hermenêutica e(m) Crise: uma exploração da construção do Direito. $11^{\mathrm{a}}$ ed. Porto Alegre: Livraria do Advogado Editora, 2021.

STRECK, Lênio Luiz. Jurisdição constitucional e hermenêutica: uma nova crítica do direito. Porto Alegre: Livraria do Advogado, 2002.

TARUFFO, Michele. La Prueba Sobre Los Hecho, Colección Estructuras y Processos. Tradução de Jordi Ferrer Beltrán. Imprenta: Madri, 2009. 